\title{
11
}

\section{PARTICIPATORY DESIGN AS CONCEPT AND PRACTICE IN THE EXPERIMENTAL MUSEUM: THE CASE OF THE WORKERS MUSEUM}

\author{
Anne Scott Sørensen
}

The Workers Museum was established in 1982 by means of the National Workers Union (LO) and supported by the Municipality of Copenhagen and from 1984 also by the Danish State. The museum is situated in the original Workers Assembly Building amid the capital, the oldest in Europe and second oldest in the world. It was raised by the early Workers Union in 1879 and is part of a transnational initiative of Workers Assembly Buildings applying for UNESCO's tentative list of world heritage (Bak-Jensen \& Jensen, 2018; Ludvigsen, 2013). The Museum was, in 2019, awarded the European Museum Academy Award DASA for excellence in learning opportunities and for 'engaging particularly children and youngsters in the fundamental learning process of political action' (European Museum Academy, 2019).

In the case study, I focus on the upcoming exhibition Activist! to be launched in February 2021. The exhibition includes the peer-initiative Museum Rebels to start out already in 2018 with workshops at schools and with youth organisations all over the country, and includes the during the exhibition ongoing Protest Workshop, a physical installation and learning centre during the exhibition. The Museum Rebels initiative is supported by the Ministry of Culture and the Protest Workshop by the Roskilde Festival's call on 'Young Voices' 2019. The museum won the call due to the scheduled activities to 'train the activist talents of youngsters, strengthen community-building and keep democracy alive' (Roskilde Festival, 2020). ${ }^{1}$ Both the DASA and the 'Young Voices' committee point at the fact that the museum is experienced in working with youngsters between 13 and 25 from upper secondary schools, high schools and vocational schools, and have them co-produce and even to some extent co-curate exhibitions such as the former Unheard Youth (2015-2016).

In Denmark and the Nordic countries, as in other parts of the world, museums have turned to participation as a strategy to transform the museum as public institution (Eriksson et al., 2020; Gether et al., 2017; Schwartz \& Sørensen, 2018; Sørensen, 2016). However, only a few have up till now taken the strategy into the 
very core of the institution and considered participatory design an option. Even if museums since long have pledged a widened understanding of participation to not only address how to transform visitors into participants but also how to enroll them already in the initial phases of planned activities, participatory design is of yet rather unexplored in theory and practice. Worldwide, reported experiments in museums are yet few, Nina Simon's practise-based take on The participatory museum as defined through processes of co-creation and co-decision coming closest (Simon, 2010). The argument here is that for museums to work with participatory design, it is necessary to consider it a concept in the sense that the Dutch cultural critic, curator and artist Mieke Bal has suggested. According to Bal (2002), a thorough investigation into what a concept might mean simultaneously is an investigation into what it might do. Part of the task, in this case, is to clarify the interrelatedness of the two concepts.

\section{Participatory design and participation as twin concepts}

Participatory design and the broader concept of participation are, in Bal's (2002) sense of the word, travelling concepts that move across disciplines and across research and practise. They are subject to contestation but also to cross-fertilisation when used as a means of interdisciplinary exploration and reflection. They are useful 'not so much as firmly established univocal terms but as dynamic in themselves' and due to the fact that 'while groping to define, provisionally and partly, what a particular concept may mean, we gain insight into what it can do' (Bal, 2002, p. 11). Keeping this in mind, it is worth having a closer look the way the two concepts have travelled between different fields of knowledge production and discursive domains to grow into what might be understood as a twin concept. In the following mapping, three international readers are marked as stepstones. They point to how the two concepts have derived from similar scientific and social roots and taken much the same routes since the mid-twentieth century. The first reader starts from the participatory design end, whereas the latter two starts from the participation end.

In the Routledge international handbook of participatory design (Robertson \& Simonsen, 2013) the concept is traced back to the various social, political and civil rights movements of the 1960s and 1970s in U.S.A. According to the editors, designers and design researchers, at first within urban planning and since within information technology and computer system design, responded to this by investigating how they might relate the new ideas to their own practices and working conditions. The project was further pioneered in Europe and especially in Scandinavia as part of what became known as the workplace democracy movement during the 1970s. Since then it has evolved into a distinct concept to signify 'the direct involvement of people in the co-design of the artefacts, processes and environments that shape their lives' and thus been extended from workers and the workplace to 'ordinary' citizens and public life (Robertson \& Simonsen, 2013, p. 2). Accordingly, participatory design is not defined by formulas, rules and strict 
definitions but by a commitment to core principles. These, in turn, are informed by a rich heritage of projects, methods, tools and techniques from specific design contexts. The defining principles as listed by Robertson and Simonsen (2013, pp. 3-10) are:

1. To take a stand

2. Genuine participation

3. Mutual learning

4. Practice

5. Design

The first means to give primacy to human action and people's rights to participate in the shaping of the worlds, in which they act, and make design about designing futures for actual people. The second implies a fundamental transformation of the users' role from being merely informants to being legitimate and acknowledged participants in the design process. Following from these two, mutual learning and the setting up of mutual learning processes are further defining commitments. These basic principles next lead to questions such as: what does participation mean in terms of actual power to make decisions; who needs to participate and how can this be managed and supported; how can the design process itself be designed so people can participate in it; and what kinds of design tools and methods is needed? (Robertson \& Simonsen, 2013, p. 5). The whole project still rests on the dual principles of practice and design to reinforce the interplay of creative and intellectual forces and enhance 'reflection-in-action.' In the end, the list discloses a dynamic paradox and implicit challenge: reverberating at the edge of design and participation, professional skills and democratic objectives.

Prior to the reader in participatory design, quoted above, social anthropologist Andrea Cornwall edited The participatory reader (Cornwall, 2011). She argues that the concept is basically about transformative political action and that it, inspired by the radical social movements of its time, took shape in social and community research from the early 1960s and 1970s. Basically, the concept is about autonomous social action, generated from below. However, the reader among others includes urban planner Sherry Arnstein's still much cited article 'The ladder of citizen participation' (Arnstein, 1969). The article presents 'a ladder' of participation in relation to public governance: from the lower (non-participatory) end of manipulation and therapy through the middle part (tokenism) of consultation and placation until the upper end (citizen power) of partnerships and delegated power and at the very top full citizen control (Arnstein, 2011 [1969], p. 217). Cornwall concludes that participation has come to include certain forms of 'invited' participation by governmental or non-governmental agencies, the intention of which allegedly is a distribution of power, but which has also made it a more ambivalent concept (see also Cornwall, 2008).

Unlike the former two, the reader The participatory cultures handbook (Delwiche \& Henderson, 2013) traces the heritage of participatory cultures as a cultural 
phenomenon. Again, the origins are found in the social movements of the 1960s and 1970s, including a computer underground that goes even further back to the late 50s and is closely connected to the rise of the so-called New Left (Delwiche, 2013). The reader predominantly is about how new digital cultures have evolved from these roots and today take more mundane forms. Kelty (2013) argues that in order to address todays digital cultures it is important to distinguish between media, technologies and platforms, and trace how they relate to other concepts such as formal social enterprises and organised publics in order to explore the way specific media technologies and platforms 'distribute rights, power, and resources' (Kelty, 2013, p. 27). He further argues that whereas participation was first understood to benefit the participants, it is now also expected to effect institutions, organisations and technologies. He concludes, that 'participation is no longer simply an opening up, an expansion, a liberation, it is now also a principle of improvement, an instrument of change and a creative force that cuts across different societal arenas.' Consequently, 'it no longer threatens, but has become a resource: participation has been made valuable' (Kelty, 2013, p. 24).

Yet other crossroads between social, technological and natural science research and practice have arisen to contribute to the conceptual work, for instance in new interdisciplinary knowledge fields such as sustainability and climate. At these new crossroads the twin concepts meet other concepts such as citizen science and citizen 'sensing.' Researchers within these fields document how participation is already included in everyday practices understood as inter-actions of objects, technologies and humans, and argue that sustainability and climate actions may tap in on such practices to again re-enforce them by providing conceptually grounded procedures, tools and techniques (Gabrys, 2017; Marres, 2012). They also argue that such processes are multi-faceted and the outcome equally multi-valent (Lury \& Marres, 2015). One of the prerequisites of participatory design is that while it generates unexpected surplus and side effects, it is also unpredictable and imbued with mistakes and errors.

What comes across this short mapping of the field is, for the one thing, that participation and participatory design are performative concepts to imply a transformative action that involves people, things/technologies and procedures. Next, it has also become clear that such transformative processes are open and multi-dimensional and even messy to be guided not only by a mutual investment in the process but also a considerate outline and explicit communication. A point, I shall pursue in the following section on how the twin concepts have travelled into museum studies and museum practice.

\section{Participatory design and participation in museums}

The basic ideas and principles of participation were translated into a museum context in the late twentieth century (Weill 1999). Since then, the enrollment of visitors in museums has been at the agenda as means to transform visitors as well as museums and revitalise their relevance as public institutions (Simon, 2010, 2016). 
Simon (2010) refers to Arnstein's 'ladder of participation' and lays out some progressive steps for the museum to take from different forms of visitor contribution through different types of co-creation and co-decision onto hosting diverse community-generated initiatives. Simon does not rank the different steps, though, but considers them equally legitimate instruments to engage the public, and to be chosen between with a view to the specific museum, context and situation. She thereby also suggests establishing a more flexible and even pragmatic approach.

Pruulmann-Vengerfeldt and Runnell (2011), on their side, underscore museums' obligation to take the lead in societal transformative action and suggest an explorative approach by which visitors are made partners in 'experimental knowledge laboratories.' Taking this idea further, Sitzia (2020) introduces the related concept of public agency. She challenges the phrasing of Simon and others that museums today constitute a public contact zone to instead put the alternative claim forward that they equally are, and should be, a conflictual zone or 'battlefields of agency' (Sitzia, 2020, p. 186). Agency, then, implies 'a tense field of practice' in terms of collectives of stakeholders struggling to have their intentions met and mirrored in the outcome: besides professionals, museum departments, public authorities and eventually private agencies not least visitors conceived as citizens and local communities. This is to be felt most intensely in terms of the participatory step, that Sitzia wants to add to Simon's list, namely that of collection management by which the public is given a widened authority to enter the professional engine room and the level of museum governance. Sitzia accordingly speaks of a 'composite' agency but does not unfold the implications in any detail. Instead, she calls for a diversity of participatory practices to go beyond the laddermodel-way-of-thinking. She underscores that also collection management can take many forms, depending on context and situation. Nevertheless, her message is that to trigger the kind of public agency, she argues for, a rigorous design of participatory activity in each museum, exhibition, etc. is needed even if the process itself still must be open and directed by the mutual investment (Sitzia, 2020, p. 188).

What Sitzia calls attention to here, is the dynamic paradox which arises from the performative quality of participatory design, that for transition to happen there must be a considerate script with a clear sequel and transitory passage points. Along with this argument, Dufrasne and Patriarche (2011) suggest thinking of participation as participatory genres that constitute organising structures and establish repertoires of elements to be adjusted to the specific purpose. They also suggest that they may be analysed - and designed - according to six dimensions: why (purpose), how (degree), what (sequence), who/m (ratification), when (frequency) and where (location). Even if participation planning seems to be a conceptual oxymoron, success is claimed to depend on the degree of informed preparation and modulation. In the following, I shall suggest a method that takes a middle ground in balancing the more idiomatic and the more pragmatic, the more prescriptive and the more explorative approach to participatory design. 


\section{An applied model for design analysis and practice}

The approach, which I shall pursue, stays with the radical visions of participatory design, embedded in the former listed normative principles to supplement them and make them a set of well-described analytic and prescriptive criteria (Kelty et al., 2015). It presents a ' 7 dimensions-take' on participatory design that is developed in the context of informational technology, but which is applicable to other contexts. The intention is to guide research-based practice in a widened field of participatory design by providing a prescriptive methodology that demonstrates the normative basis of the agenda but also provides a concrete tool for analyses and implementation while still leaving room for experimentation. The seven dimensions as listed by Kelty et al. (2015, p. 475) are as follows:

1. The educative dividend of participation

2. Access to decision making and goal setting in addition to task completion

3. The control or ownership of resources produced by participation

4. Its voluntary character and the capacity for exit

5. The effectiveness of voice

6. The use of metrics for understanding or evaluating participation

7. The collective, affective experience of participation

The first point settles learning as a vital part of participation and is concerned with not only content but as much with the learning process itself, including learning how to participate through participation. Kelty et al. thus distinguish between what they call new skills and 'civic virtue,' respectively, to designate the ongoing, mutual process of democratic education. The second point highlights that taking part in decisions has, on the one hand, to be anchored in factual task completion and, on the other hand, stretch into the goal-setting agenda of the task in question. It, again, is interdependent of the specific organisation and whether it takes the form of formal social enterprises or organised publics (to be further explained in Kelty, 2013). Museums as public institutions necessarily belong to the former and need to negotiate how far they can go in terms of their flexibility.

The third point is decisive, however often overlooked in practice: it is about the control and ownership of resources produced by participation. Often, they are also not easy to define since they take intangible forms. Maybe more surprising, the fourth point concerns a crucial right to withdraw from the process - without penalty but still with resources. The fifth point, again, is an absolute prerequisite since the issue of 'voice' is one of the most central capacities for participation in deliberative democracy (Kelty et al., 2015, p. 482). Still, it might also be slippery as a right to 'speak out' without negative consequences and in order to influence the very outcome of the task or process in question. It is also often not made visible and made feasible by feedback mechanisms. To nail it down, it is according to the authors necessary to have a sixth principle of metrics that monitors the collective as well as the individual outcome and makes the gain of participation visible to the 
participants as well as the organisation. The final, and seventh, principle cuts across the former and maybe is the one principle that is best attuned to today's demandside of participation: that of collective, affective and communicative experience. It is related to Cornwall's notion of collective action and Sitzia's notion of public agency to here underscore the dimensions of affective, mutual engagement. The authors refer to the sociologist Emile Durkheim's term 'collective effervescence' that designates an intense feeling of collective transition.

\section{The case study at the Workers Museum}

In what follows, I shall take the Workers Museum as a case and put focus on the triple initiative of the exhibition Activist!, the partnership with young Museum Rebels and the Protest Workshop as an installation and activity center during the exhibition. The case is chosen due to the museum's advances in democratic education as argued by the DASA and the 'Young Voices' committee, respectively. On this ground, the triple initiative is considered a critical case in Flyvbjerg's (2006) sense of the word, meaning that the object of study will most likely show some of the characteristics of the outlined principles of participatory design. Next, the case is exploratory, in the sense put forward by Yin (2014), meaning that it is partaken to explore the analytical and advisory power of the framework. The question, the case study is designed to answer, is whether and to what extent the chosen framework for participatory design is instructive as an analytic and practice-oriented tool.

The case study builds due to the COVID-19 shutdown of Danish museums from March to June 2020 on the digital archives of the museum website, a Zoom interview with the two involved curators ${ }^{2}$ and a FaceTime interview with a Museum Rebel. ${ }^{3}$ As argued in recent discussions on digital methods, the videobased online interview comes close to the physical face-to-face interview but have both advantages and disadvantages in comparison. Even if semi-structured by intention, it is often more firmly orchestrated, which was also the case here, but also often supplemented by written comments during the interview and often more open to subsequent clarifications in writing and by email (O'Connor \& Madge, 2017; Salmons, 2016). The main interview with the curators was partaken as a recorded one-hour interview to be followed by clarifying questions and deepening answers, including access to non-public documents such as applications and exhibition manuscript. The interview with the trainee was a half hour, taperecorded interview to be followed by a short SMS-exchange. All interviewees have given informed consent and chosen to not be anonymous. They have further confirmed citations (trainee) and the way, they are referred to (curators).

To the context of the case study is to add, that the Workers Museum from the very start has been situated in a conflict zone due to its origin and purpose, and during the years been critically observed by the political right as well as the political left beyond the Social Democratic Party (Ludvigsen, 2009). In order to navigate in this politised climate, the museum has up till now given high priority 
to their permanent interieur exhibitions of worker housings and working sites and less attention to the political history of the labor movement that is so closely connected to the history of the Social Democratic Party (Enstrøm \& Stender, 2019; Ludvigsen, 2009). However, the strive to have the building on UNESCO's tentative list and a donation of 16 mill. Danish crowns to restore the by tradition rich Banquet Hall ${ }^{4}$ have put the labour movement and its history of organisation and political struggle at the front to be actualised in a new national as well as global context. The so-called Arabic spring, the new democratic movements in southern Europe, and recent global youth and climate activism are all signals of new political openings. This is to be felt in a recent visitor study, according to which they ask the museum to stand by its heritage and put its values up front. ${ }^{5}$

It now seems timely for the museum to introduce the triple initiative of the exhibition Activist!, the organisational setup of the Museum Rebels and the combined installation and training center of the Protest Workshop. The aim of this triple initiative is to engage visitors and particularly youngsters in the roots and routes of democracy and contribute to democratic revitalisation. Within the overall take of this article, the question is to what degree or in what sense the outlined framework of participatory design is useful to analyse the way this triple initiative has been taken forward but also whether it would possibly fertilise the yet ongoing process. One overall challenge in applying the model is that the initiative is composed of a range of partnerships to include, at the one end, a university-based research group ${ }^{6}$ and 30 activist interviewees, and, at the other end, a range of school classes and groups from youth organisations - the so-called Museum Rebels. ${ }^{7}$

I shall in the following analyses focus on the partnerships with school-classes and other groups of organised youth as Museum Rebels to take the form of a range of workshops to also prepare the Protest Workshop as concept, practise and installation during the exhibition. Each group of youngsters is enrolled at different stages and in different parts of the initiative and in such a way that the outcome, in the first place, rests within each group and workshop. Still, the initial workshops are meant to define the basic questions to be raised in the exhibition, whereas the later workshops are meant to take on a continued dialogue with the exhibition in such a way as to enhance a flow between workshops and between them and the exhibition to form a bigger imaginative collective of Museum Rebels.

\section{The triple initiative: Activist!, Museum Rebels and Protest Workshop}

The exhibition Activist!, planned to open in February 2021, has been in the pipeline for several years to be prepared partly through the above-mentioned research project, partly through initial workshops with school classes and other groups of youngsters to constitute a first 'wave' of Museum Rebels. The research project on Danish left-wing political activism asks how Danes engage in politics and relate to various forms of activism in the timespan 1960-2020. It includes a survey with respondents to represent the Danish population $(N=2500)$ as well as 
in-depth interviews with 30 self-declared living activists, involved in different types of political action from the anti-nuclear marches via the peace movements' sit-downs onto today's school strikes Fridays for Future. The material will be displayed in the exhibition in the form of statistics and excerpts from the survey, filmed and recorded interviews with the activists and 'talks' with the researchers. These original materials will be supplemented by documents, artefacts and audiovisual reportages to further enlighten the documented stories and events. Besides, the initial workshops with first wave Museum Rebels will be integrated in the exhibition in different ways for instance as citations on wall stickers that represent a present-day view on the issues, brought to the fore by the historic material. Throughout the exhibition, the voices of the different partners/participants are put in dialogue. Also, the museum visitors will be encouraged to engage, take a stand and make their voices heard in various ways throughout the exhibition. As to the overall purpose of the exhibition, it is stated by the curators that:

The aim of the exhibition is to appreciate people's democratic, activist engagement from the point of view that activists contribute to keeping democracy alive through their work. The museum does neither hail nor condemn specific forms of activism but provides a room where activists' own voices are heard, where the Danish population's general approach towards activism are communicated on the ground of new research, and where the visitors to the exhibition are invited to reflect and take a stand as to what they think activism is, can and should be. (K. Kamp-Albæk, e-mail exchange with author, 22 May 2020)

The overall priority on behalf of the museum thus is giving voice (principle 5) to the different partners/participants: survey informants, activist interviewees, museum rebels and eventually 'ordinary' visitors, and have them fertilise each other in different ways to enhance a mutual educative dividend (principle 1). The different partners do not come together as a manifest social collective but rather as contributors to an imaginative collective of museum rebels to ideally have a communal experience of participation (principle 7) - even if not direct 'access to decision making and goal setting in addition to task-completion' (principle 2) or 'control or ownership of resources produced by participation' (principle 3). Or rather these principles rest with the way, the different groups are enrolled, first and foremost the Museum Rebels of the initial as well as the subsequent Protest Workshops.

What came forth in the interview with the museum professionals is that the basic take on the exhibition has grown out of the early workshops with Museum Rebels and the enrollment of young trainees during the early planning process. It is these early activities, starting out already in 2018, that have gradually formed the take on the exhibition to have the rebels have an imprint on the basic script. The Museum Rebels have as an institutional setup and ongoing activity been established before the present initiative to be now taken further as a continuous part of the museum's educational activities to enforce the democratic Bildung of youth. The reasoning 
behind is that even if Danish youth according to several surveys are among the most democratic informed in Europe, they are still underrepresented in public debate and governance and often doubt their own democratic mandate and right to have a voice. In the context of the Activist! exhibition, the Museum Rebels are made an integral part of the process from the very start and thus a part of the initiating design process. The youngster, I interviewed, was a young 8th-grade trainee, who as part of her job had to take part in the National Youth Assembly 2019 and engage peers in the issue of political activism. Besides she was asked to critically evaluate the at the time ongoing exhibitions and present her ideas for the professionals to implement in the upcoming exhibition. According to the trainee, she felt enthusiastic about the way she was listened to and heard: 'They even took a lot of notes,' she said. Asked about her own outcome, she commented that it gave her a new enthusiasm for and way of learning civics as her chosen school subject. She still stays informed about the museum and has joined a later exhibition on communism with her school class, even if she does not explicitly identify with the term Museum Rebel - 'it is more a word for the way the engage young people,' she reasons.

Up till now the Museum Rebels-initiative has primarily been with partners in the region of the capital, but in the context of the Activist! exhibition school classes as well as youth organisations all over the country have been invited to participate in initiating workshops through an open call. The purpose has been to identify the core questions of and the take on the exhibition by which present-day understandings of political engagement can be challenged with a view to how it might look like in the future. The early workshops are further meant to establish three platforms for the subsequent Protest Workshop each of which to generate a range of activities. One of the ideas that, according to the curators, has come up is to have the concept more permanently established as an alternative to the in Denmark school-based preparation for Christian confirmation (7th to 8th grade) to instead have a certificate as educated democrats.

Asked about the most visible imprint of the early Museum Rebels on the exhibition, the curators answer that what has come across the different workshops in the early phase is that activism basic means to take a stand and act upon it. It was generally phrased by the youngsters as a question of 'head' and 'heart' to interact and come out through 'the hands.' This bodily choreography has been grasped to form the basic design of the exhibition as a transformative journey with a sequel of steps to be taken, materialised as a movement through four exhibition rooms: (1) the personal stories of activists with an emphasis on motivation, choices and emotional engagement; (2) a synchronic display of different activist causes, formats and tools; (3) a diachronic outline of six decennials of activism in context of their time and the road taken from beginning to end; (4) reflection on means and ends, testing how far the actual museum visitors would go themselves: for what, with what means and at what price. The exhibition journey ends with the Protest Workshop as a platform to take on new action. In all sequences, the voices of the different partners/participants are blended and mixed with different types of materials, objects and media. In order to mark the presence of the Museum Rebelsall 
the way, stickers with citations and formed as hearts, heads and hands guide - and challenge - throughout.

Whether visitors would enter The Protest Workshop is vocational as is the booked sessions in the installation with museum educators and activists (principle 4). The Protest Workshop is thought of as partly a physical installation in the exhibition, partly a dynamic zone for multiple youth-centred teaching activities and programmes during the exhibition. In these new workshops, youngsters from schools, organisations and associations will meet people with different experiences and competencies and learn how to plan campaigns, raise debates and agitate, to in the end choose a burning question to be addressed and practice the skills themselves. The exact design of the installation is yet on the sign board to take the form of a literal as well as digital workshop in which visitors can transform into activists and produce their own remedies. One of the inspirations is found in a historic toolbox from the Socialist Youth Front $(\mathrm{SUF})^{8}$ with all the elements needed for their activities during election campaigns from sprays and stencils to fabrics for banners.

The rationale of the Protest Workshop is a learning-by-doing experiment by which first and foremost the enrolled youngsters can perform as protesters and experience an instant outcome of their engagement. Each workshop is participatory in the sense that the outcome is defined by the youngsters to take part in it. Possible outcomes would be production of posters, podcasts or campaigns on social media to be also included in the exhibition along the way. As to the principles of participatory design, the core principles 2 and 3, concerned with goal setting, ownership and control of resources, are an integrative part of each single workshop. It is less obvious how they inform the overall initiative since it is up to the museum professionals to orchestrate the interchange. This again leaves the museum with a moral obligation to be acted upon by attuning to the tone and voice of the involved youngsters. Besides, the Museum Rebels have suggested a broader definition of activism to be taken by the curators, including subjects such as animal welfare, vegetarianism and food trashing as well as actions such as speaking up in class, in the school yard or at home. Finally, a 'wishing well' of due causes has been created to gather further visions from incoming (young) visitors.

\section{Conclusion: participatory design in the experimental museum}

Returning to the seven prescriptive criteria listed previously (Kelty et al., 2015, p. 475), it has become clear from the analyses of the triple initiative that the principles 1-3 are met within each partnership and workshop to also influence the exhibition even if in different ways and to different degrees. The early Museum Rebels have had a rather deep impact on the design of the exhibition Activist! already at the initial conceptual level. The youngsters, who are going to be involved during the exhibition and in the Protest Workshops, will have their ideas worked out immediately. All are enrolled in a limited space of time, and thus are not part of the process all the way through. This makes sense since we are speaking of youngsters 
and for the bigger part of school classes and even school extinction classes to whom the engagement necessarily is timed. It nevertheless underscores that the influence on goals and control of resources is primarily cashed at the micro-level of workshops. To some participants, it will without doubt have consequences for their sense of ownership and specific identification as museum rebels as also seen in the interview with the trainee (principle 7). As the analyses have put forward, the multiple voices nevertheless contribute each their way to shaping a broader vision and affective engagement to also be felt and sensed in the interviews. Thus, the principles 1-3 and 7 can be said to be met as a basic imprint on the atmosphere and mood of both exhibition and workshops. Principle 4 - voluntariness - is a basic criterion of all three legs of the initiative, even again at the level of the school class and for the teachers to also be responsible for. Criterion 5 - voice - is the criterion accounted most consistently for by the curators and in the analysis. Not only the voices of the young rebels, but also the voices of researchers, survey-respondents, activists and visitors to reinforce or challenge each other, and shape a joint engagement with burning questions and a will to change. Criterion 6 - the use of metrics to valuate participation - again is a tricky one not only in the partnerships with schools and youngsters but in them all and as a general challenge to participatory design in public institutions. During the interview with the curators, this led to an open discussion of possible feedback mechanisms to secure that not least the youngsters/school classes experience to have contributed, how and with what. It might also contribute to the institution's/ museum's own evaluation. To have more explicit measures for the outcome and value of participation and of the gain, when using participatory design methods, seems crucial in order to stipulate what a participatory design practice in fact can do to an exhibition and to the institution now and in the future.

Overall, the case study has shown the seven-dimensions model to be a relevant tool for a practice-oriented analysis and demonstrated how it can be done. It has helped balance the normative and pragmatic perspective and bring the conceptual coherence and practical implications forth to also point to where practice can be qualified. It has been a limitation of the case study that the voices of the Museum Rebels have not been heard with the same consistency as that of the curators. It would no doubt have brought other aspects to the fore if not changed the direction of the analyses and suggestions. What the seven-dimensions criteria are less suited for is to deliver a straightforward typology in the tradition of Arnstein's classic ladder-model or as seen in newer and more flexible graphic models such as triangles, stars, etc. It can also not tell how to adjust to specific types of museums or specific user groups and partners. The strength of the seven-dimension model lies within it not being a model but a dynamic set off criteria. Due to the solid anchoring in the conceptual heritage of participation and participatory design, it constitutes a guide and checklist for each museum to take on, elaborate and adjust, when the specific circumstances, intentions and range of activities are considered and accounted for. Even if the concept now has half a century on its back, it is still on the go to scaffold the experimental museum and the continued work on the 'design of design.' As put forward in the introduction to Museum Activism 
(Janes \& Sandell, 2019), seeking to purposefully bring about social change today, although the idea remains controversial, is the way many visitors, museum professionals as well as governmental bodies think about the roles and responsibilities of museums as knowledge-based social institutions, even if with differing ends.

\section{Notes}

1 The prize was 1.4 million DKK. According to the museum, the title Protest Workshop might be changed to Activist Workshop.

2 The interviewees are the curators Kristine Kamp-Albæk and Kristine Møller Gårdhus. Programme director Linda Nørgaard Petersen took part in an e-mail exchange, before and after.

3 The interviewed museum rebel, Karen Anna Kroon, was an 8th-grade trainee (aged 14) from spring 2019. She was pointed out to me by the curators, a fact which has to be taken into account when weighing her contribution.

4 Composed of a grant from the Augustinus Foundation (10 million DKK) and the AKF Foundation (6 million DKK).

5 The museum in 2018 engaged with a private consulting agency (OPERATE) to have a visitor study. The report is not public, but referred to by Enström and Stender (2019).

6 The research project 'Grassroots, protesters and extremists: Political leftwing activism 1960-2020' (2018-2020) was conducted by professors Lasse Lindekilde and Thomas Olesen at The Department of Political Science, University of Aarhus, and archivist at The Workers Museum Jesper Jørgensen.

7 According to the museum, 1,074 pupils distributed across 33 school classes and 23 schools and a few other groups at the museum have been enrolled up till now (May 2020). Further workshops are scheduled for the autumn 2020.

8 SUF is the informal youth section of the political left-wing party 'Enhedslisten,' represented in the Danish Parliament.

\section{Bibliography}

Arnstein, S. R. (2011). A ladder of citizen participation. Journal of the American Planning Association, 35(4), 216-224.

Bak-Jensen, S., \& Jensen, M. (2018, 9 April). Folkets huse: Fællesskabets verdensarv [The people's houses: The world heritage of the community]. Berlingske. https://www. arbejdermuseet.dk/kronik-folkets-huse-faellesskabets-verdensarv/

Bal, M. (2002). Travelling concepts in the humanities: A rough guide. University of Toronto Press.

Carpentier, N. (2011). The concept of participation: If they have access and interact, do they really participate? CM Communication Management Quarterly, 6(21), 13-36.

Cornwall, A. (2008). Unpacking 'participation': Models, meanings and practices. Community Development Journal, 43(39), 269-283.

Cornwall, A. (2011). Preface. In A. Cornwall (Ed.), The participatory reader (pp. xii-xx). Zed Books.

Cornwall, A. (Ed.). (2011). The participatory reader. Zed Books.

Delwiche, A. (2013). The new left and the computer underground: Recovering political antecedents of participatory culture. In A. Delwiche \& J. J. Henderson (Eds.), The participatory cultures handbook (pp. 10-21). Routledge.

Delwiche, A., \& Henderson, J. J. (Eds.). (2013). The participatory cultures handbook. Routledge. Dufrasne, M., \& Patriarche, G. (2011). Applying genre theory to citizen participation in public 
policy making: Theoretical perspectives on participatory genres. CM Communication Management Quarterly, 6(21), 61-86.

Enstrøm, L. M. S., \& Stender, L. M. (2019). Arbejdermuseets fremtidige formidling: Arbejdermuseets omstillingsproces fra etablering frem til $i$ dag [The future communication strategy of The Workers Museum], MA thesis, University of Southern Denmark.

Eriksson, B., Stage, C., \& Valtysson, B. (Eds.). (2020). Cultures of participation: Arts, digital media and cultural institutions. Routledge.

European Museum Academy. (2019, 21 September 2019). 2019 EMA awards. Press release. file:///C:/Users/annescott/Downloads/Press-Release-2019-European-Museum-AcademyAwards.pdf

Flyvbjerg, B. (2006). Five misunderstandings about case-study research. Qualitative Inquiry, 12(2), 219-245.

Gabrys, J. (2017). Air walk: Monitoring pollution and experimenting with forms of participation. In C. Bates \& A. Rhys-Taylor (Eds.), Walking through social research (pp. 144-161). Routledge.

Gether, C., Jalving, C., \& Høholt, S. (Eds.). (2017). The art of taking part. ARKEN Bulletin 7. https://www.arken.dk/wp-content/uploads/2017/04/bulletin-2017_lowres.pdf

Janes, R. R., \& Sandell, R. (2019). Posterity has arrived: The necessary emergence of museum activism. In R. R. Janes \& R. Sandell (Eds.), Museum Activism. Routledge.

Kelty, C. M. (2013). From participation to power. In A. Delwiche \& J. J. Henderson (Eds.), The participatory cultures handbook (pp. 22-32). Routledge.

Kelty, C. M., Panofsky, Aa., Currie, M., Crooks, R., Erickson, S., Garcia, P., Wartenbe, M., \& Wood, S. (2015). Seven dimensions of contemporary participation disentangled. Journal of the Association for Information Science and Technology, 66(3), 474-488.

Ludvigsen, P. (2009). History of the Workers' Museum in Denmark. International Labor and Working-Class History, 76, 44-53.

Ludvigsen. P. (2013). Workers' assembly halls as a proposition for UNESCO's World Heritage. International Journal of Heritage Studies, 9(5), 908-938.

Lury, C., \& Marres, N. (2015). Notes on objectual valuation. InM. Kornberger A. Koed Madsen et al. (Eds.), Making things valuable. Oxford University Press.

Marres, N. (2012). Material participation: Technology, the environment and everyday politics. Palgrave.

O'Connor, H., \& Madge, C. (2017). Online interviewing. In N. G. Fielding, R. M. Raymond, \& G. Blanck (Eds.), The SAGE handbook of online research methods (pp. 416-434). SAGE.

Pruulmann-Vengerfeldt, P., \& Runnell, P. (2011). When the museum becomes the message for participating audiences. CM Communication Management Quarterly, 6(21), 159-179.

Robertson, T., \& Simonsen, J. (2013). Participatory design: An introduction. In T. Robertson \& J. Simonsen (Eds.), International handbook of participatory design (pp. 1-17). Routledge.

Roskilde Festival. (2020, 16 April). Press release. https://presscloud.com/csp/vocast/ message.csp?KEY=489870174634570

https://slks.dk/fileadmin/user_upload/0_SLKS/Dokumenter/Museer/Museumsvirksomhed/ Kvalitetsvurdering/Arbejdermuseet._Kvalitetsvurdering_2018.pdf

Salmons, J. (2016). Cases in online interview research. SAGE.

Schwartz, C., \& Sørensen, A. S. (2018). Artivism and the para-institution; The Partisan Café and Museum of Burning Questions, Bergen Assembly 2016. The Journal of Nordic Museology 2/3, 121-135.

Simon, N. (2010). The participatory museum. Museum 2.0.

Simon, N. (2016). The art of relevance. Museum 2.0. 
Sitzia, E. (2020). Public participation and agency in art museums. In B. Eriksson, C. Stage, \& B. Valtysson (Eds.), Cultures of participation: Arts, digital media and cultural institutions (pp. 185-200). Routledge.

Sørensen, A. S. (2016). Participation: The new cultural policy and communication agenda. Nordic Journal of Cultural Policy, 19(1), 4-18.

Weill, S. E. (1999). From being about something to being for somebody: The ongoing transformation of the American Museum. Daedalus, 128(3), 229-258.

Workers Museum, The (n.d.) Homepage. https://www.arbejdermuseet.dk/en/

Yin, R. K. (2014). Case study research (5th ed.). SAGE. 